\title{
A Formação de professores e o ensino de ciências no ensino fundamental
}

\section{Teacher training and the science teaching in elementary education}

\author{
Keycinara Batista de Lima, Douglas Willian Nogueira de Souza \\ Universidade Federal do Amazonas - Instituto de Educação, Agricultura e Ambiente - Brasil
}

\begin{abstract}
Resumo
O objetivo é realizar um levantamento sobre a formação de professores e suas visões acerca do ensino de ciências, especificamente física, nas séries iniciais. No anseio de responder a problemática foram entrevistados cinco discentes e três docentes do curso de Pedagogia da Universidade Federal do Amazonas do campus de Humaitá, a respeito da visão que eles apontam em relação à disciplina de ciências durante sua graduação e seu reflexo na escola e alfabetização científica. As entrevistas mostraram uma imensa preocupação entre teoria e prática. Embora seja muito discutido na formação, ainda há ausência quando o assunto é interdisciplinaridade.

Palavras-chave: ensino de ciências, ensino fundamental, formação de professores.
\end{abstract}

\begin{abstract}
The present paper aims to carry out a research upon the teacher formation and its concerns about the teaching of Sciences, specifically Physics, in the Elementary School classes. In order to have some questions answered, five students and three teachers were interviewed, all of them from the course of Pedagogy at the Federal University of Amazonas in its campus in the city of Humaitá, to understand what are their considerations about the subject of Sciences, along their formation and its reflection over the school and the scientific literacy. The interviews showed a great preoccupation between theory and practice. Although this is greatly focused during the formation course, there is a gap to be fulfilled as for the interdisciplinarian themes.

Keywords: teaching of Sciences, Elementary School, Teacher formation.
\end{abstract}

\section{Introdução}

Atualmente, as crianças desde os primeiros anos escolares lidam de forma direta ou indiretamente com assuntos de ciências naturais. Nesta perspectiva, levando em consideração que tais conceitos constituem o currículo escolar desde os anos iniciais da escola básica, como nos mostra Portela e Higa, percebe-se que eles ainda são vistos de forma exordial nas séries iniciais.

De acordo com os Parâmetros Curriculares Nacionais no primeiro ciclo do ensino fundamental, o ápice é a interdisciplinaridade, fundamentada na visão construtivista e contextualizada, estando disposto em três blocos temáticos: Ambiente; Ser Humano e Saúde; e Recursos Tecnológicos. Contudo, é sabido que o ensino de ciências naturais, especificamente física, é incomum nestes anos. Corroborando com tal afirmação, Chaves e Shellard (2005) enfatizam que hoje são reconhecidas as dificuldades de se realizar um bom ensino de ciências nas escolas, um ensino que integre ciências aos conhecimentos científicos e que tais dificuldades vêm aumentando à medida que descemos no nível de escolaridade.

Os motivos para esta ocorrência são vários: infraestrutura; professores sobrecarregados; pouca carga horária de aulas, dentre outros, entretanto delimitamonos neste ensaio à formação do professor e suas metodologias em sala de aula. (CHAVES; SHELLARD, 2005).

Cachapuz, (2005), nos mostra que quando se trata de renovação no ensino de ciências "precisamos não só de uma renovação epistemológica dos professores, mas que essa venha acompanhada por uma renovação didáticometodológica de suas aulas" (CACHAPUZ, 2005, p.10).

Não é conveniente que alimentamos nossos alunos de conceitos científicos dados como verdades absolutas, isto não é fazer ciência, este processo é o que Paulo Freire denomina de educação bancária. Fazendo isto estaremos oferecendo-lhes conhecimento em forma de "fast food". E é bem provável que não conseguirão desenvolver pensamentos críticos e científicos a partir destes.

Apesar da grande importância do saber científico e da imensa evolução em que se encontra a sociedade, estamos diante da grande falência na qual caminha o estudo e ensino de ciências naturais, principalmente na maioria das escolas brasileiras. Para consolidar essa linha de pensamento Cachapuz (2005) nos diz que

Essa participação, na tomada fundamentada de decisões, necessita por parte dos cidadãos, mais do que um nível de conhecimento muito elevado, a vinculação de um mínimo de conhecimentos específicos, perfeitamente acessível a todos, com abordagens globais e considerações éticas que não exigem especialização alguma. (CACHAPUZ, 2005, p. 25).

A realidade é que nem sempre os professores estão preparados para essa fundamentação. A busca pela formação continuada está tendo grande repercussão, no entanto, vagarosamente chega às salas de aulas. Mesmo com o grande avanço das tecnologias, o acesso aos recursos comunicativos e a necessidade em renovar o ensino, a renúncia dessas atribuições parece ainda estar presente no dia a dia escolar. 
O impacto no Brasil em relação ao ensino de ciências da natureza e suas tecnologias é considerável, contudo, está defasado, como afirma Maldaner (2006):

[...]. Parece que os resultados da investigação e as soluções apontadas não chegam às salas de aula. Atribui-se esse fato ao despreparo dos professores, à sua prática acomodada de "dar aula", às condições de trabalho, às orientações curriculares instaladas nas escolas, à falta de material para o ensino e outros. (MALDANER, 2006, p. 50).

O desafio da própria mudança causa a maior parte da resistência presente nos docentes. Muitas vezes levado pelo desgaste físico e psíquico, pela desvalorização socail em nosso país e por não acompanhar os avanços tecnológicos ligados à informática e à mídia televisiva, dentre outros.

O ensino de ciências não se resume simplesmente em sala de aula, conteúdos para integralização da educação básica e desenvolvimento de tecnologias. A alfabetização científica contribui para o desenvolvimento social e pessoal, este fato não implica que todo estudante que se interesse por assuntos relacionados à Física, à Biologia ou à Química tende a ser futuro cientista. Neste contexto, a criança crescerá formando um elo entre seus conhecimentos pré-formados e o conhecimento científico em si.

Assim, trata-se de obter decisões fundamentadas diante da sociedade, de formar cidadãos críticos e fundadores de suas próprias personalidades, de amenizar,ou até disseminar a alienação, como mostra Rosa, Perez e Drum (2007):

Os Parâmetros Curriculares Nacionais para o Ensino Fundamental compartilham dessa premissa ao mencionarem que as ciências naturais no bojo curricular das séries iniciais devem buscar um ensino que permita aos estudantes compreender o mundo e atuar como indivíduos críticos e participativos, utilizando conhecimentos de natureza científica e tecnológica. Nessa perspectiva, o documento aponta para a potencialidade de serem vinculados tais conhecimentos ao aspecto do desenvolvimento afetivo, dos valores e das atitudes, que devem estar presentes no ensino de ciências como forma de conceber oportunidade de encontro entre professor, aluno e o mundo, reunindo a vivência dos estudantes e proporcionando meios para que ultrapassem o senso comum e apontem para a construção do conhecimento científico. "Se a intenção é que os alunos se apropriem do conhecimento científico e desenvolvam uma autonomia no pensar e no agir, é importante conceber a relação de ensino e de aprendizagem como uma relação entre sujeitos, em que cada um, a seu modo e com determinado papel, está envolvido na construção de uma compreensão dos fenômenos naturais e suas transformações, na formação de atitudes e valores humanos" (BRASIL, 1997, p. 33, apud, ROSA; PEREZ; DRUM, 2007).

Em uma pesquisa investigativa realizada, Maldaner (2006) traz as falas de duas professoras da rede pública estadual, registradas em um dos encontros sistemáticos de formação continuada com professores de ciências, em setembro de 2004:

Professora A: (...) isso que nós falamos aqui na universidade, não tem nada a ver com o que acontece lá na escola. E o que está acontecendo no ensino lá na escola não tem nada a ver com isso que a gente está falando. E é por isso que outros colegas vêm aos encontros. Eles dizem que não querem vir. [...], mas, eles dizem que isso, aqui, é perda de tempo, que isso nunca vai poder ser aplicado lá na escola. Lá cada um trabalha com o seu conteúdo de sempre. (...). Professora B: O problema está na Licenciatura. Na universidade que formou a gente, tudo o que a gente aprendeu, no curso, e até na especialização, tudo é dentro de cada disciplina. $\mathrm{E}$ na escola é a mesma coisa. E a cobrança vem. [...] (MALDANER, 2006, p. 63).
Partindo desses registros, observamos o quão relevante é o estudo voltado para a formação continuada do professor e o ensino de ciências nas séries iniciais, visto que ela, muitas vezes, é vista como um mito, ou como uma realidade inalcançável.

\section{Traçando o caminho}

De frente a essa temática e no anseio de iniciar uma caminhada no contexto educacional na região sul do Amazonas, utilizamos o ambiente acadêmico da Universidade Federal do Amazonas para subsidiar nossa pequena investigação que servirá de suporte a outros trabalhos vindouros.

Após contatarmos alguns docentes do colegiado de Pedagogia, três professoras se disponibilizaram para nos relatar sobre sua visão e experiência quanto ao ensino de ciências, especificamente os assuntos que abordam conceitos de física, nas séries iniciais. Para fundamentar e complementar nossos dados, entrevistamos cinco alunos da graduação do curso de Pedagogia da mesma instituição, com o seguinte critério: ter cursado a disciplina que aborda os assuntos de ensino de ciências, pois, julgamos que após o discente ter cursado a disciplina, ele, assim, poderia ter subsídios necessários para expressar sua visão frente à temática.

A fim de mantermos a identidade de nossos sujeitos seguros, os professores foram denominados por números e os alunos por letras.

\section{O ensino de ciências naturais focalizando a física na perspectiva docente superior}

Como já mencionado, para dar suporte à nossa pesquisa, três professores dispuseram relatar suas visões e experiências quanto à formação docente no curso de Pedagogia e o ensino de ciências nas séries iniciais.

A professora 1 é formada em Pedagogia desde 1987, durante sua formação cursou três disciplinas sobre o ensino de ciências e trabalha há dez anos no ensino superior. Nunca ministrou a disciplina de Ensino de Ciências na graduação, somente na educação básica, no ensino médio e no antigo magistério para professores de primeira à quarta série. A professora relata que quando se trata de métodos na disciplina trabalhava-se mais aspectos didáticos, criação de jogos. Nas palavras dela:

Porque é um conhecimento considerado como base, mais o senso comum, trabalhar com figuras, experimentos simples, observação de campo, não muito aprofundado, por exemplo, germinação, temperatura, sabores, odores, água, as características da água, os estados físicos da água, são conteúdos que são trabalhados na educação infantil e está ligado à física. (PROFESSORA 1).

Corroborando com esta afirmação, Pinto (2007) afirma que o jogo é uma atividade muito conhecida e trabalhada na carreira acadêmica, enfatiza também o resultado que ele pode desenvolver quando se trata de inter-relação pessoal, ao ser aplicada em grupo. No entanto, ressalta o cuidado que deve ter em usá-lo. "É necessário que o jogo não perca, em sua prática, o aspecto educativo em prol apenas do lúdico, mantendo assim, o objetivo central, focado na relação ensino-aprendizagem." (PINTO, 2009, p. 27).

Como sugestão de ação perante a grande escassez que se encontra o ensino de ciências naturais, 
especificamente física, nos primeiros anos do ensino fundamental, a professora afirma:

É complexo, pois a quantidade de professores habilitados em física, diante das necessidades do país e da região é pouca. Temos uma demanda imensa e uma oferta incipiente, insuficiente, até para o ensino médio não temos professores suficientes, imagine para a educação infantil e o ensino fundamental. (PROFESSORA 1).

$\mathrm{Na}$ visão da docente, a sugestão seria projetos específicos, quando ela fala: "Interessante seria a formação continuada para os professores [...], o desafio seria: em que horário? Então deveria criar uma política onde os professores pudessem trabalhar em serviço, porque o profissional habilitado para atender a demanda no Brasil não há!" (PROFESSORA 1).

De acordo com Silva; Souza; Dourado e Begy (2005), a sociedade e o conhecimento estão em constante movimento, de modo que a formação continuada esteja na lista de um bom desempenho educacional. Sendo assim, quanto ao profissional preocupado com a aprendizagem e esse constante avanço no mundo do trabalho, "será preciso achar formas de continuar aprendendo sempre para desenvolver-se profissionalmente." (SILVA; SOUZA; DOURADO E BEGY, 2005, p. 13).

Quando falamos sobre o curso oferecer apenas uma disciplina, a professora diz que desde que ela seja bem feita dará suporte para que o futuro docente trabalhe ciências nas séries iniciais, no entanto, de forma superficial, "o ideal seria um professor habilitado para essa disciplina, o ideal." (PROFESSORA 1).

Nesta perspectiva, Delizoicov e Angotti (1994) sugerem que os professores de Metodologia do Ensino de Ciência, além de comunicar-se com os outros docentes, como os de biologia, de física e de química, consultem regularmente os textos destas outras áreas, muito possivelmente eles ajudarão em suas atividades e estreitarão esse laço entre as disciplinas.

Dando continuidade nos relatos, a professora 2 é formada em Pedagogia e Letras, concluiu sua graduação em 2008, na sua formação acadêmica cursou apenas uma disciplina que envolvesse o ensino de ciências, a saber Teoria e Prática no Ensino de Ciências, no entanto, nunca ministrou a disciplina no ensino superior. Com sugestão de ação perante a grande escassez que se encontra o ensino de ciências naturais, especificamente física, nos primeiros anos do ensino fundamental, a professora afirma:

Entendo que nas disciplinas de ciências: a física, a química, a biologia, existem vários elementos que acompanham esta disciplina ciências lá nas séries iniciais, acredito que o principal viés desta formação da criança lá na escola tem que surgir aqui da preparação da universidade, uma coisa puxa a outra, então a formação do professor deve estar voltada pra este ensino de ciências lá na escola. (PROFESSORA 2).

Podemos perceber nesta fala que há uma implicação direta da formação do professor com seu papel na escola, como afirma Delizoicov e Angotti (1994): "Os cursos de licenciatura plena, mesmo com as suas deficiências e ainda que necessitem de maior atenção para o ensino de $1^{\mathrm{a}}$ a $4^{\mathrm{a}}$ séries, capacitam minimamente para a atuação profissional no campo pedagógico e didático." (DELIZOICOV; ANGOTTI, 1994, p.19).

Diante do exposto, a professora 2 acredita que a universidade tem papel fundamental nesta formação.

Não é trabalhar física dentro de ciência, [...] só por trabalhar, tem que ter um contexto interdisciplinar. Para fazer isto o professor tem que estar preparado, e uma forma de preparar o professor são os conhecimentos prévios adquiridos aqui na formação superior, para ele fazer essa ponte entre a teoria e a prática. (PROFESSORA 2).

Por fim, a professora 3 graduou-se em Pedagogia em 1987, teve uma disciplina de Metodologia de Ciências, trabalha no ensino superior há 11 anos. Quando a indagamos sobre qual ação perante a grande escassez que se encontra o ensino de ciências naturais, especificamente física, nos primeiros anos do ensino fundamental, a professora afirma que "os professores que ministram aula nos anos iniciais na grande maioria, quase $100 \%$, não tem noção de física, na verdade os professores sentem dificuldade em abordar os conteúdos".

Ela continua dizendo que, muitas vezes, os professores até dão o conteúdo, mas sem fundamento, algo mais experimental, isso acontece também com a matemática, a biologia e a química, "nós professores de Pedagogia temos muita dificuldade na área da matemática, da física, biologia, da química, e daí a gente leva em segundo plano, eu acredito que o curso de Pedagogia peca nesta formação, não só aqui, nos cursos de Pedagogia." (PROFESSORA 3).

Nesta lógica, Delzoicov e Angotti (1994) consideram que é irreal dicotomizar método - conteúdo. A disciplina ,Metodologia do Ensino de Ciências poderá materializarse de forma artificial se for somente um discurso, sendo que sua função é fundamentar o instrumento didático para o docente, a luz da criticidade.

Em sua narrativa, a professora relata um grande problema encontrado nas universidades:

Quando a gente trabalha com as crianças a questão de força, na recreação, a questão de distância, tiro ao alvo. Isso tudo é física, nós não temos noção disso, pela dificuldade que a gente tem de trabalhar com os outros colegas formadores dos outros cursos, por exemplo, de física, biologia e de química, a gente não consegue interagir para melhorar a formação do pedagogo. (PROFESSORA $3)$.

Corroborando com esta narrativa, Pereira (1999) enfatiza a extrema importância de se criar no âmbito acadêmico, principalmente nos cursos de licenciatura, "uma cultura de responsabilidade colaborativa quanto à qualidade da formação docente, nas palavras do autor." (PEREIRA, 1999, p.117).

Diante do modelo político e socioeconômico brasileiro vigente, as universidades públicas assumem o desafio e o compromisso de exercer uma nova cultura institucional nos cursos de formação de professores, que é formar profissionais da educação com intuito de transformar a educação básica no Brasil.

\section{O ensino de ciências naturais focalizando a física no olhar dos graduandos}

Para discorrer sobre as expectativas e experiência durante a graduação, realizamos entrevista no modelo semiestruturado com cinco graduandos que já cursaram a 
disciplina referente ao ensino de ciências nas séries iniciais.

Quando instigados a relatar sobre sua visão acerca do ensino de ciências, especificamente física, como futuro docente, obtivemos as seguintes narrativas:

A discente A alegou que o ensino de ciências não é somente a questão de experimentos, atividades práticas. Quando as ciências são utilizadas de maneira significativa, ocorre o que chamamos de alfabetização científica, tema que é muito abordado no curso de Pedagogia.

Diante disso, Chassot (2003) destaca a alfabetização científica como intensificador alternativo que desencadeia uma educação comprometida. Para ele, a ciência é uma linguagem, e a alfabetização científica é "saber ler a linguagem em que está escrita a natureza. É um analfabeto científico aquele incapaz de uma leitura do universo. ". Conceber a ciência contribui para história e prevê as transformações que advém da natureza. Com isso, podemos acarretar uma melhor qualidade de vida tendo por base essas transformações. (CHASSOT, 2003).

A discente B aponta em suas falas a possibilidade de abordar os conceitos físicos nas salas de aulas: "a gente trabalhou com jogos, não iria trabalhar muito conceitos, traria sim, no início, os conceitos para as crianças saberem como a ciência surgiu, e a partir dos jogos e da criatividade de cada um como futuro docente.”.

Podemos observar que há a presença dos jogos, contudo, o fundamento desse jogo se encontra em segundo plano. Justamente esse cuidado em abordar jogos em sala de aula Pinto (2007) frisa sobre importância deles, porém chama atenção quanto à sua fundamentação vinculada aos objetivos da aula e do conteúdo relacionado. Como a futura docente menciona que "devemos sempre ir em busca, como Paulo Freire diz, ir além dos seus conhecimentos e não ficar na mesmice.".

Através desta afirmativa, Pereira (1999) descreve a postura do professor investigador e ressalta a importância desta metodologia ser instigada desde a graduação. "Isso significa que as universidades devem assumir a formação do "professor investigador", um profissional dotado de uma postura interrogativa e que se revele um pesquisador de sua própria ação docente." (PEREIRA, 1999, p.118).

A estudante C ressalta a importância do ensino de ciências e a relevância em contextualizá-lo, onde ela diz: "porque é a partir das ciências que nós conhecemos as bases da sociedade, abordar esses assuntos nos anos iniciais desencadeará a base para você viver em um mundo melhor, não é só não jogar lixo na rua, é tudo".

Testificando a fala da discente podemos citar os Parâmetros Curriculares Nacionais, PCNs, que é um documento orientativo educacional brasileiro, no qual trata as ciências como fator que potencializa e desenvolve a criticidade diante da sociedade. O objetivo central é "colaborar para que essas transformações que envolvem o nosso cotidiano sejam conduzidas para que tenhamos melhores condições de vida." (CHASSOT, 2003, p. 91).

Nas palavras da graduanda D temos:

A formação da gente eu diria que é limitada, essa discussão sobre o ensino de ciências, até porque muita gente sai daqui pensando que ensinar ciências é ensinar apenas ciências naturais e não leva em consideração que existem várias ciências. (ALUNA D).

Podemos perceber que a questão levantada pela entrevistada se trata da interligação dos saberes, interdisciplinaridade. Fazenda (2008) traz a definição de interdisciplinaridade segundo o CERI, Centro para Pesquisa e Inovação do Ensino, que a descreve como sendo a "interação existente entre duas ou mais disciplinas" (FAZENDA, 2008, p. 94).

A autora ainda menciona que interdisciplinaridade escolar remete às noções, finalidades, habilidades e técnicas objetivando proporcionar o processo de aprendizagem, levando em consideração os conhecimentos prévios do aluno. A discente acredita que se o gosto por estudar física não é resolvido no ensino fundamental, no ensino médio ela terá um desvio na aprendizagem, e, muitas vezes, esse desvio torna insatisfatório esse ensino, "e ele se torna dogmático, muito tradicional, as pessoas não gostam disso, não gostam se quer da matemática, que é passada desde as séries iniciais, agora imagina física, que nem nas entrelinhas não é passada. Eu mesmo passei por isso, e hoje isso ainda continua.".

É nítida a indignação da estudante quando relata sua experiência e qual ontinua se propagando num ciclo vicioso. Elencamos aqui a importância da relação teoria e prática trazida por Delizoicov e Angotti (1994), a formação docente deve haver em seu âmago a prática e a teoria interligadas, caso contrário, os objetivos almejados serão insuficientes.

Por fim, a discente E afirma que o ensino de ciências é muito importante, destaca que teve apenas uma disciplina: Metodologia das Ciências nos Anos Iniciais onde foram estudados diversos métodos de como ensinar ciências para as crianças, alguns conceitos básicos, como decomposição.

Quando interrogamos sobre a quantidade de disciplinas a aluna expôs o seguinte relato:

No meu ponto vista não é suficiente somente uma disciplina. A universidade em si não está preocupada com a qualidade, a gente pode se perguntar por que só uma disciplina? Porque não diminuir a carga horária de outras e, assim, oferecer mais disciplinas? Talvez não seria nem oferecer mais disciplina, mas sim de unificar as disciplinas. Acredito que falta muito isso ainda na universidade, frisar os conhecimentos que podem ser unificados e ter relação. Se está dentro da ciência, também faz parte dos outros conteúdos abranger a ciência, acredito que falta muito para Pedagogia se expandir, porque se o professor não for atrás a universidade pouco oferece subsídios. (ALUNA 5).

Observamos na narrativa da discente a desvinculação entre a realidade da comunidade com a universidade. São muitas pesquisas que precisam chegar até aqueles que realmente interessam, a escola. Pensar em educação diante de um cenário globalizado e infuenciado por políticas neoliberais é, antes de tudo, pensar na formação do professor como um agente capaz, valorizado e mediador do processo de aprendizagem.

\section{Conclusão}

Os resultados apresentados neste ensaio são parte de uma pesquisa que teve como objetivo realizar um levantamento sobre a formação de professores e suas 
visões acerca do ensino de ciências, especificamente física, nas séries iniciais no municipio de Humaitá, sul do estado do Amazonas.

Pode-se perceber, com base nas narrativas dos professores, uma imensa preocupação entre teoria e prática. Eles destacam a importância dos conceitos de física na formação básica dos pequenos, entretanto, faltam-lhes embasamento teórico.

A pequisa mostrou que os cursos de formação de professores não são sucifientes para dar segurança a esses profissionais em sala de aula, isto é, os cursos polivalentes não estão abarcando toda especificidade de conteúdos que um professor deve ter.

Das narrativas dos alunos, emerge a preocupação do futuro profissional para desempenhar tantas responsabilidades em sala de aula.

Nesse sentido, a maioria dos discentes elencam a formação continuada como possibilitadora de preencher as lacunas deixadas pela formação inicial.

Assim, durante o desenrolar do artigo elecamos o ensino de ciências como um conteúdo importante no processo de aprendizagem, principalmente nas séries iniciais, como forma de minimizar dificuldades em séries futuras, porém, não queremos colocá-lo como o único potencializador da aprendizagem, pois consideramos que todas as disciplinas têm sua importância, além disso, acreditamos que a interdisciplinariedade é um caminho para que o aluno perceba a ciência com um todo, e não em partes fragmentadas.

\section{Referências}

Cachapuz, António. (2005). A necessária Renovação do Ensino das Ciências. 3 ed. São Paulo: Cortez.

Chassot, Attico. (2003). Alfabetização científica: uma possibilidade para a inclusão social. Revista Brasileira de Educação, [s. L.], n. 22, p.89-100. Mensal. Disponível em: $<$ http://www.scielo.br/pdf/rbedu/n22/n22a09.pdf $>$. Acesso em: 12 jun. 2017.

Chaves, Aloar; SHELLARD, Ronalda Cintra. (2005). Física para o Brasil: pensando o futuro. São Paulo: Sociedade Brasileira de Física.

Delizoicov, Demétrio; ANGOTTI, José André. (1994). Metodologia do ensino de ciências. São Paulo: Cortez. 207 p. (Formação de Professor).

Fazenda, Ivani Catarina Arantes. (2008). Interdisciplinaridade e transdisciplinaridade na formação de professores. Ideação, Foz do IguaÇu, v. 10, n. 1, p. 93-10. Semestral. Disponível em: <http://erevista.unioeste.br/index.php/ideacao/article/view/414 6>. Acesso em: 12 jun. 2017.

Maldaner, Otavio Aloisio, et al. (2006). Pesquisa sobre educação em ciências e formação de professores. In:A pesquisa em Ensino de Ciências no Brasil e suas Metodologias. Ijuí: Unijuí. p. 49-88.

Pereira, Júlio Emílio Diniz. (1999). As licenciaturas e as novas políticas educacionais para a formação docente. Educação \& Sociedade, [s. L.], n. 68, p.109-125. Disponível em: $<$ http://www.scielo.br/pdf//es/v20n68/a06v2068.pdf>. Acesso em: 12 jun. 2017.
Pinto, Leandro Trindade. (2007). O uso dos jogos didáticos no ensino de ciências no primeiro segmento do ensino fundamental da rede municipal pública de duque de caxias. 132 f. Dissertação (Mestrado) - Curso de Programa de Pós-graduação Stricto Sensu em Ensino de Ciências, Instituto Federal de Educação, Ciência e Tecnologia do Rio de Janeiro, Nilópolis 2009, 2009. Cap. 6. Disponível em: $<$ http://www.ifrj.edu.br/webfm_send/3039>. Acesso em: 12 jun. 2017.

Portela, Caroline Dorada Pereira; HIGA, Ivanilda. Os estudos sobre ensino de física nas séries iniciais do ensino fundamental. Disponível em: < http://www.pucpr.br/eventos/educere/educere2007/ana isEvento/arquivos/PO-339-05.pdf $>$. Acesso em: 12 jun. 2017.

Rosa, Cleci Werner da; PEREZ, Carlos Ariel Samudio; DRUM, Carla. (2007). Ensino de física nas séries iniciais: concepções da prática docente. Investigações em Ensino de Ciências, [s. L.], v. 12, n. 3, p. 357-368. Disponível em: $<$ http://www.if.ufrgs.br/ienci/artigos/Artigo_ID176/v1 2 n3 a2007.pdf $>$. Acesso em: $11 \mathrm{dez} 2016$.

Silva, Andresina Ma da; SOUZA, Delvair Mendes de; DOURADO, Ghiusa Silva e BEGY, Hella Rita de Araújo (2005). Formação continuada de professores. 2005. Projeto de Trabalho de Conclusão de Curso. Disponível em: $<$ http://repositorio.uniceub.br/bitstream/235/6759/1/40 300316.pdf>. Acesso em: 12 jun. 2017.

\section{Agradecimientos}

Agradecemos à coordenação de Aperfeiçoamento de Pessoal de Nível Superior - CAPES pelo incentivo financeiro dado aos fins da realização desta pesquisa. 